\title{
Ian Brown
}

\section{Some Vacuum-Arc-Based Plasma and Ion Beam Tools for Surface Modification}

\begin{abstract}
Vacuum arc discharges provide a copious supply of dense metal plasma, and this kind of plasma source has gained wide acceptance as a standard laboratory tool. Plasmas can be formed from virtually all of the solid metals of the Periodic Table as well as carbon, and by admitting a controlled flow of gas into the arc region hybrid gas/metal plasmas can be formed also. This plasma formation mechanism has been incorporated within an ion source configuration to provide a means for generating energetic high current beams of metal ions - the metal vapor vacuum arc ion source. Here we describe four specific embodiments of the vacuum arc plasma source for the surface modification of materials - plasma deposition of thin films; metal ion implantation; plasma immersion ion implantation and deposition; and implantation using the «inverted ion source» concept.
\end{abstract}

Keywords: vacuum arc, metal plasma, surface modification, ion implantation.

doi: $10.21293 / 1818-0442-2017-20-4-7-13$

The vacuum arc is a discharge between metallic electrodes in vacuum in which plasma is formed from the substance of the cathode material [1-4]. Dense metal plasma streams away from the cathode at an ion energy in the range of about 10 to $200 \mathrm{eV}$ (ion velocity of about $1-3 \mathrm{~cm} / \mu \mathrm{s})$, depending on the cathode material used, in a direction mostly normal to the cathode surface [5]. In developments that have taken place at a number of laboratories around the world, this kind of plasma source has been utilized in a variety of ways for the surface modification of materials, encompassing the synthesis of thin films and multilayer structures via plasma deposition, and the formation of surface and near-surface buried layers of otherwise unattainable alloys of synthesized composition via energetic ion implantation [6] as well as hybrid kinds of surface modification that interleave or mix both of these deposition and implantation techniques [7, 8].

Because the metal plasma from a vacuum arc is created as a jet that streams away from the cathode [5, $9,10]$, this plasma source itself, unadorned by any further elaboration, provides a «metal plasma gun» - a device for generating energetically streaming metal plasma. This affords an excellent, and quite simply made, means for the energetic deposition of thin film structures. Considerable effort world-wide has been given to the utilization and exploration of this plasma deposition technique.

High energy beams of metal ions can be formed by embodying the vacuum arc plasma source within an ion source (i.e., an ion beam generator) configuration [1117]. Then the metal plasma provides the «feedstock» for the ion beam. The ion beam current can be very high, and currents of up to $20 \mathrm{~A}$ have been reported [18]. At the same time, the extraction voltage employed in these kinds of ion sources can be up to around $100 \mathrm{kV}$, and since the vacuum arc ions are multiply stripped with charge states typically in the range $1+$ to $5+[16,19,20]$ the ion energy of the extracted ion beam is greater than the extraction voltage by the same factor. Ion beam energy can be up to several hundred $\mathrm{keV}$. As a tool for surface modification, the vacuum arc ion source has been used widely for high energy, high dose, metal ion implantation.

Plasma Immersion Ion Implantation ( $\left.\mathrm{Piii}_{\text {or }} \mathrm{Pi}^{3}\right)$ is an alternative method of implantation in which the energetic ions are provided by acceleration across the high voltage sheath established around the biased target which is immersed within the plasma [21-24]. The target is repetitively pulse-biased to high negative voltage; during the pulse-on period energetic implantation occurs, and during the pulse-off period the plasma recovers. This technique can be used with a metal plasma provided from a vacuum arc $[25,26]$. In this case, during the pulse-off period there is some deposition of neutral metal plasma on the target, and so the process is a hybrid of metal ion implantation and metal plasma deposition. The method has been called «Plasma Immersion Ion Implantation and Deposition», or «Mepiiid», and has been used for a range of surface modification applications.

In conventional ion implantation, the ions are extracted from a plasma that is held at high positive potential, and the ion energy is determined by the potential drop through which the ions fall in the beam formation electrode system. An alternative approach has been demonstrated in which the plasma and its electronics are held at ground potential and the ion beam is formed and injected energetically into a space maintained at high negative potential [27]. This configuration has been called an «inverted ion source», and precisely because the plasma source and electronics are at ground potential, it allows substantial savings both technologically and economically, rendering feasible some ion beam implantation applications that might otherwise not be possible for researchers and laboratories of more limited means [28].

Here we describe these four specific ways of utilizing the vacuum arc plasma for the surface modification of materials - plasma deposition of thin films, metal ion implantation using a vacuum arc ion source, metal plasma immersion ion implantation and deposition, and implantation using the «inverted ion source» approach. The methods and their hardware are outlined, and examples of their applications presented. 
Vacuum arc plasma deposition

The plasma from a vacuum arc is formed as a plasma jet with directed ion energy in the range 10$200 \mathrm{eV}[5,9,10]$. Metal plasma guns driven by a vacuum arc have been made in various configurations, all of them quite simple and straightforward. Two embodiments are shown in Fig. 1 [9] - an uncooled version, and a version in which the additional features of water cooling (not always necessary) and a small magnetic field at the arc region have been included.
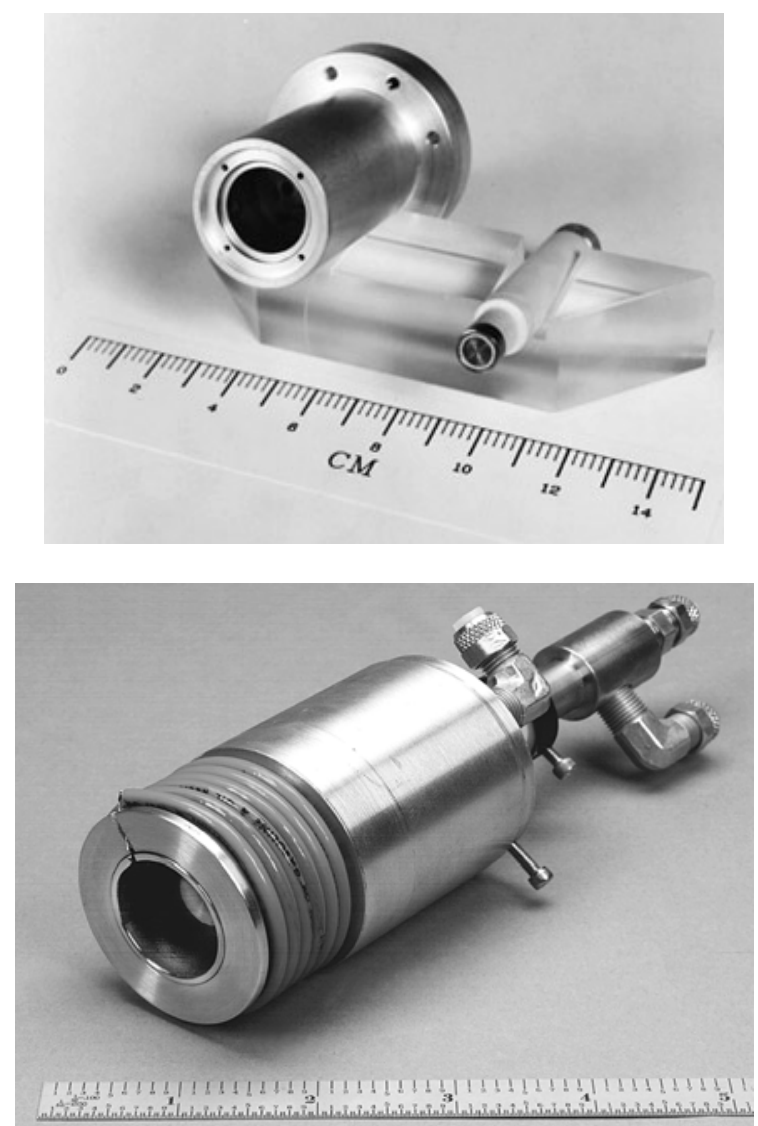

Fig. 1. Vacuum arc plasma guns. Upper: Disassembled simple uncooled version. Lower: This version includes water cooling and a small magnetic field to guide the ejected plasma stream

For the plasma deposition of thin film structures, the gun can be used «as is», but it is common practice to add a bent solenoidal magnetic field as a means of filtering out «macroparticles» from the plasma stream [29, 30]. (The vacuum arc plasma always contains some small component of «cathode debris» - small solid particle of cathode material, of dimension in the broad range about 1-100 $\mu \mathrm{m}$ [31]). A typical set-up for carrying out plasma deposition, including a macroparticle filter, is shown in Fig. 2.

Film structures formed using this approach are in general of very high quality, since the deposition is an «energetic deposition» by virtue of the intrinsic ion energy of the vacuum arc plasma. The ion deposition energy can be further controlled by biasing the substrate. By adding the appropriate gas to the deposition set-up, metal oxides and nitrides (for example) can also be formed.
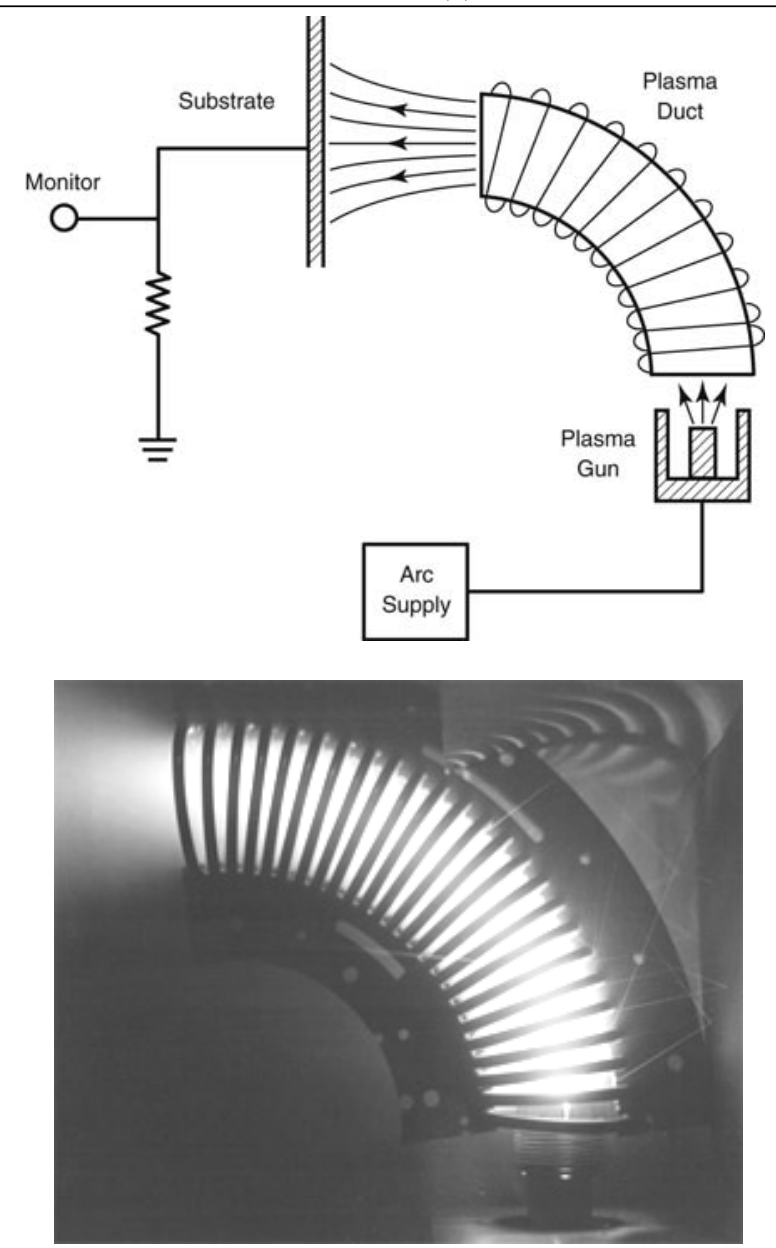

Fig. 2. Upper: Set-up for plasma deposition using a vacuum arc plasma gun with associated macroparticle filter. Lower: Photograph of plasma stream guided by a $90^{\circ}$-bent filter

This approach has found particularly nice application for forming DLC (diamond-like carbon) thin films, using a carbon cathode in the plasma gun [32, 33]. Advantages of the approach compared to other DLC deposition methods include that the vacuum arc deposited films are inherently hydrogen-free, and the ion energy can be precisely controlled so as to form films that have a very high (in fact, optimized maximally high) $\mathrm{sp}^{3}$ content (the fraction of diamond-bonded carbon as opposed to graphite-bonded carbon within the film). Fig. 3 (upper) shows the measured $\mathrm{sp}^{3}$ content as a function of carbon ion deposition energy, which is varied by biasing the substrate. It can be seen that the diamond-bonding content is as high as $85 \%$ at the optimum bias voltage of $100 \mathrm{~V}$. A further advantage of the approach is that the carbon ion energy can be controlled as a function of time throughout the deposition process. Thus the energy can be quite high in the early phase of the deposition so as to implant (bury) the carbon into the substrate and so form a broadened film-substrate interface, and then lowered to the optimum $(\sim 100 \mathrm{eV})$ during the film growth for maximum $\mathrm{sp}^{3}$. In this way the broad interface layer provides enhanced bonding of the film to the substrate, and consequently thicker DLC films can be grown without delamination from the substrate [34]; see Fig. 3 (lower). (The interface broadening approach is 
discussed further below, in the section dealing with metal plasma immersion ion implantation and deposition (Mepiiid)).
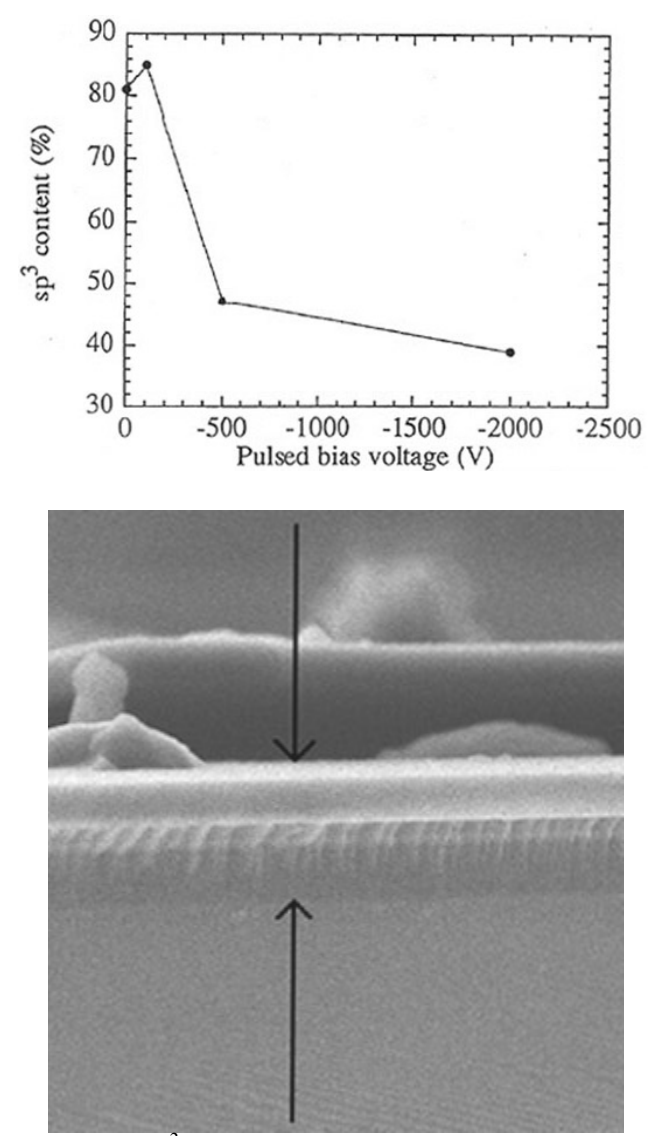

Fig. 3. Upper: $\mathrm{sp}^{3}$ content of DLC film as a function of substrate bias voltage. Lower: Cross-section scanning electron micrograph of DLC film with broadened interface with the Si substrate. The film thickness is $670 \mathrm{~nm}$

\section{Vacuum arc ion implantation}

A vacuum arc ion source (ion beam generator) can be made by incorporating a vacuum arc plasma source within an ion source geometry [11-17]. The metal plasma stream is guided toward the ion beam formation electrodes («extractor grids») where metal ions are accelerated through the extractor voltage drop. It is usual that the extractor design is a large diameter (say, several $\mathrm{cm}$ up to as much as $50 \mathrm{~cm}$ ), three-grid («accel-decel»), multi-aperture (many small «beamlet» apertures) configuration. The equivalent ion current in the vacuum arc plasma jet is about $5-10 \%$ of the arc current, and since arc currents are commonly several hundred amperes or more, the current of the ion beam extracted from the ion source can be very high indeed (depending on the extraction efficiency), and ion beam currents of up to $20 \mathrm{~A}$ have been reported [18]. The ion beam energy can be from a few $\mathrm{keV}$ up to as much as several hundred $\mathrm{keV}$, corresponding to an extraction voltage up to around 100 $\mathrm{kV}$ together with the fact that the vacuum arc ions are in general multiply stripped with a mean charge state typically $2+$ to $3+[16,19,20]$. These energies are quite sufficient for ion implantation application. Thus a vacuum arc ion source-based implanter requires no post- acceleration, and the geometry is broad-beam (not a small-diameter scanned beam as in most commercial implanters used for wafer fabrication) line-of-sight from ion source to target. Vacuum arc ion sources are typically operated in a repetitively pulsed mode, with pulse width usually several hundred microseconds and repetition rate up to several tens of pulses per second. In this way the mean power requirements and associated thermal loads are kept at manageable levels. Many different vacuum arc ion sources have been made at quite a number of laboratories around the world, and two embodiments are shown in Fig. 4 - a very small version («thumb-sized») and an embodiment forming a $50-\mathrm{cm}$ diameter ion beam [35]. The latter has demonstrated $\mathrm{Ti}$ ion beams of $100 \mathrm{keV}$ energy and beam current $20 \mathrm{Am}$ peres.
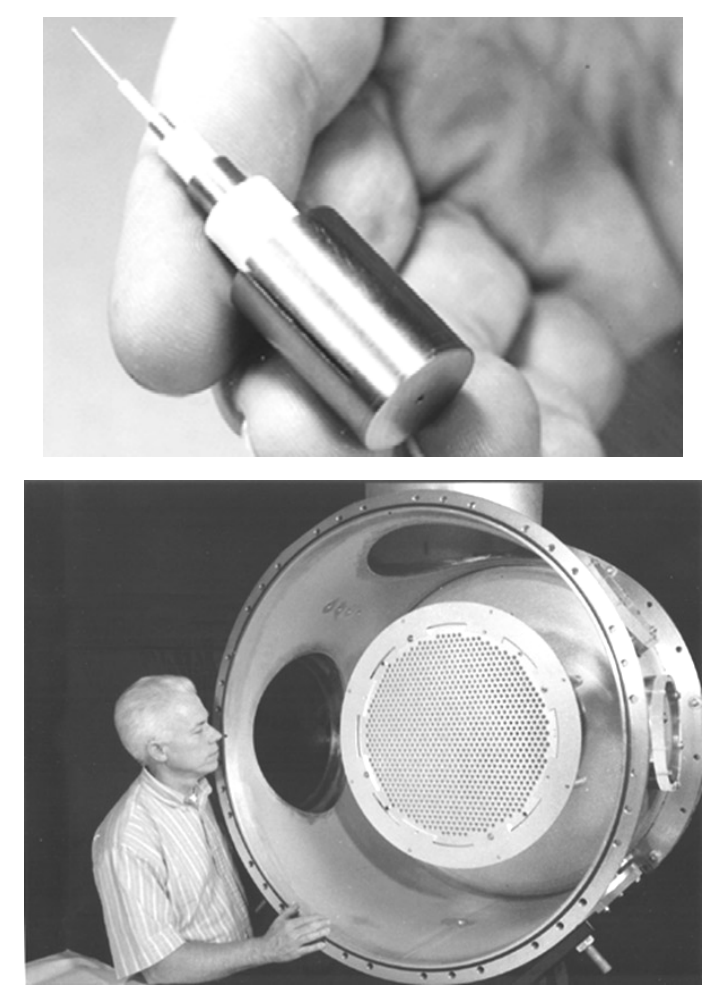

Fig. 4. Vacuum arc ion sources at two size extremes. Upper: Micro-version with beam diameter about $1 \mathrm{~mm}$. Lower: $50-\mathrm{cm}$ diameter extractor and thus beam diameter also

Vacuum arc ion source-based implanters have been used for a very wide range of implantation applications. One interesting application was to Pt-implant the interior surface of an accelerator column (the ceramic insulating section that allows the accelerator's particle source, ions or electrons, to be biased to very high voltage, typically several hundred to about $500 \mathrm{keV}$ ), so as to tailor the surface electrical conductivity of the column and thus significantly increase its maximum holdoff voltage [36]. A photograph of the ceramic column positioned in a rotating cradle attached to the implanter is shown in Fig. 5 (upper). Fig. 5 (lower) shows the measured electrical resistivity of the Pt-implanted ceramic as a function of implantation dose; thus the surface resistivity can in this way be quite accurately tailored for the specific application [37]. 

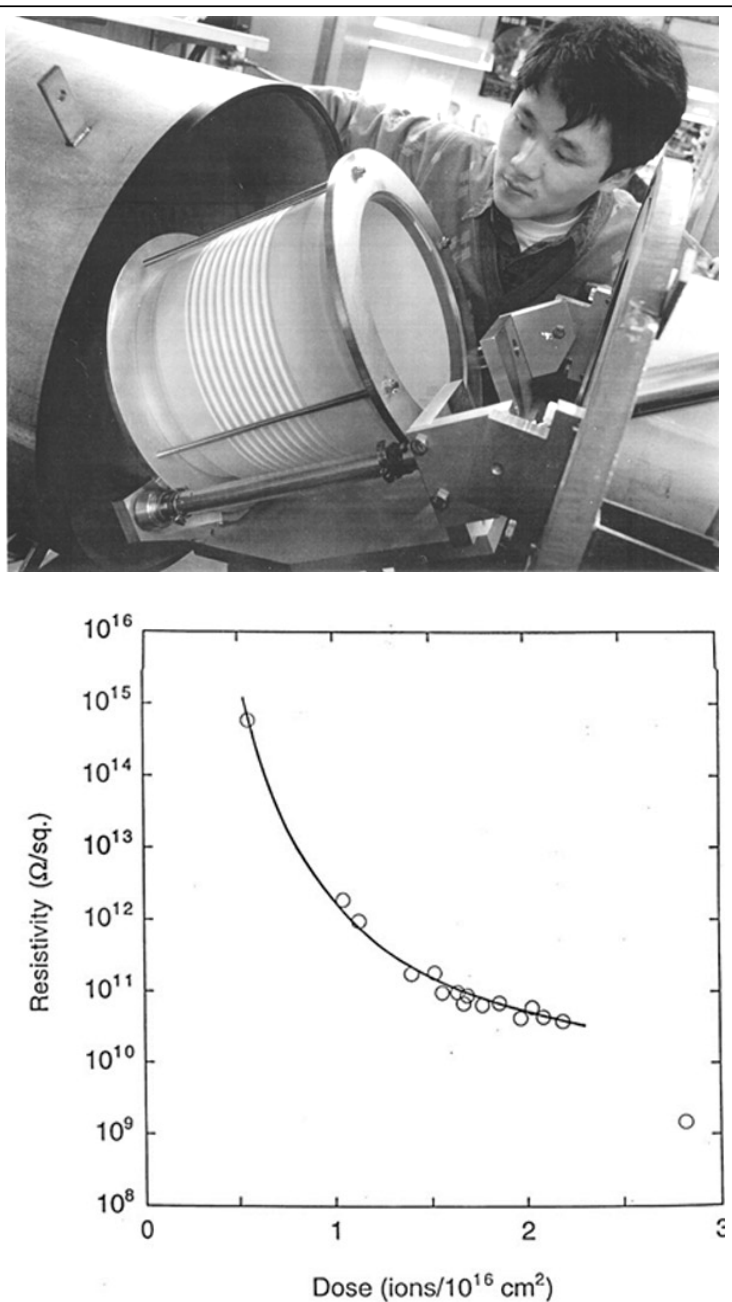

Fig. 5. Upper: Ceramic accelerator column in the rotating holder attached to the vacuum arc implanter. Lower: Measured surface resistivity of ceramic as a function of Pt ion implantation dose.

Surface modification of materials by metal ion implantation using a vacuum arc ion source has become a widely used technology at many different laboratories around the world. Much of this work has been reported at ongoing international conferences such as the IBMM (Ion Beam Modification of Materials) and the SMMIB (Surface Modification of Materials by Ion Beams), whose proceedings have been published in the journals NIM-B (Nuclear Instruments and Methods, Part B: Beam Interactions with Materials and Atoms) and SCT (Surface and Coatings Technology).

Metal plasma immersion ion implantation and deposition (Mepiiid)

Plasma immersion ion implantation, or $\mathrm{pi}^{3}$, is a technique for carrying out ion implantation of objects that circumvents the use of an energetic ion source as used in the more traditional approach [21-24]. The object to be implanted is fully immersed in a plasma and pulse-biased to high negative voltage. During the pulseon time, ions are accelerated through the high voltage sheath that surrounds the object and implanted into it, and during the pulse-off time the plasma recovers from the ion depletion thus caused. The approach has been used extensively for both research and commercial ap- plications. This technique can be adapted for use with the metal plasma generated by a vacuum arc plasma gun $[25,26]$. However, during the pulse-off period the metal plasma will condense on the target surface, and the very thin surface layer so formed (typically sub-monolayer in thickness) is subsequently bombarded by the energetic ions of the next pulse-on period and implanted by knock-on collisions. The overall depth profile of the directly-implanted and knock-on implanted species is different from the implantation depth profile formed in conventional beam-line implantation, and in general there remains some surface layer. The approach has been used in a two-gun set-up, for example to form metal-doped DLC with a graded interface to the substrate (high adhesion) [38]; see Fig. 6. The calculated depth profile (using the TRIDYN simulation program $[39,40])$ showing the graded interface between surface film and underlying substrate that can be formed by the Mepiid process is shown in Fig. 7 [34]; the broad interface that is the source of high adhesion is very clear.

\section{Inverted ion source implantation}

In conventional, or «beam line», ion implantation, an energetic ion beam is generated by an appropriate ion source and directed toward the target to be implanted. Energetic ion beams are produced by extracting ions from a plasma that is held at high potential, and the ion beam energy is determined by the potential drop through which the ions fall in the beam formation electrode system (called the «extractor» or sometimes the «accelerator») and by the ion charge state; $E_{i}=e Q V_{\text {ext }}$, where $E_{i}$ is the final ion energy, e the electronic charge, $Q$ the ion charge state, and $\mathrm{V}_{\text {ext }}$ the extractor voltage drop. It is thus an inherent part of the approach that the ion source and its associated plasma-formation electrical system, often complex, be maintained at high potential. This necessity contributes vastly to the complication and expense involved in setting up an ion implantation facility.

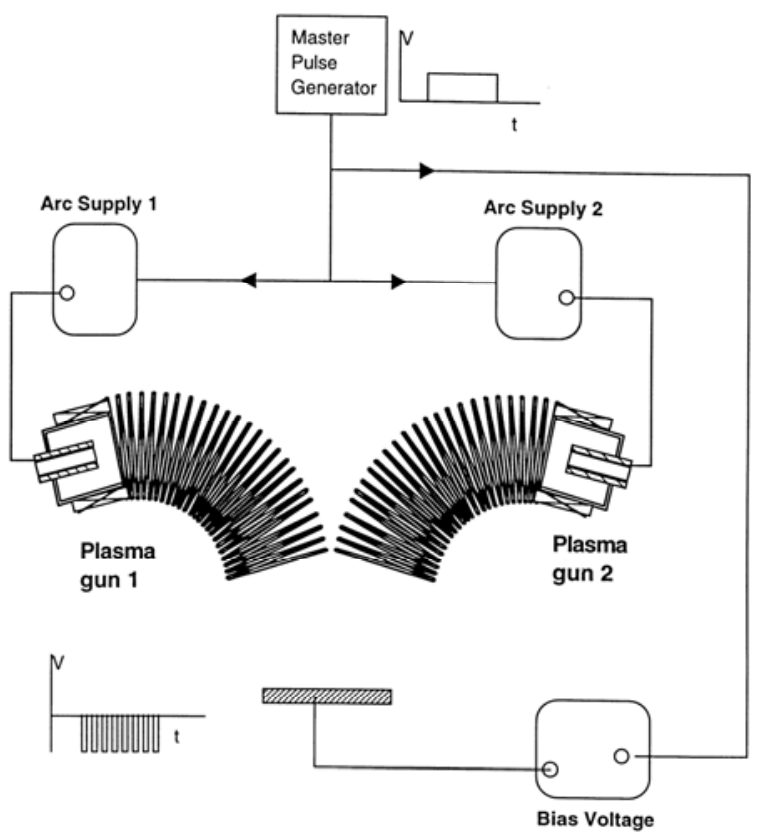

Fig. 6. Mepiiid set-up with two plasma guns 


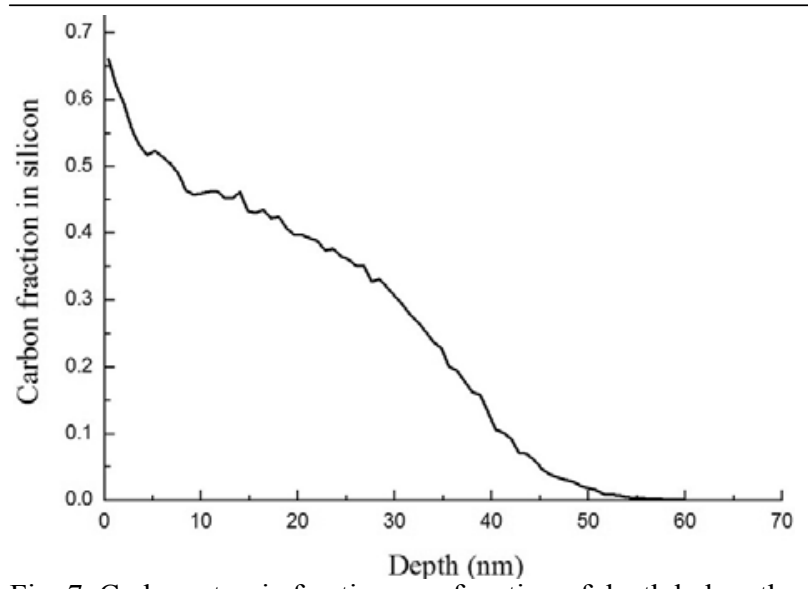

Fig. 7. Carbon atomic fraction as a function of depth below the surface, showing the graded interface formed by the Mepiiid process. This provides very strong adhesion of the surface film to the substrate [34]

An ion implantation system in which the plasma and its electrical system (the ion source) can be maintained at ground potential would provide technological and economic advantage. This can be done by maintaining the final grid and the space into which the beam is injected at high negative potential. In this case the extractor voltage drop remains high and so also the ion energy, but with the overall potential profile falling from ground to high negative voltage rather than from high positive voltage to ground. Such an arrangement, in which the implantation target must be held at high voltage, may not always be feasible, but for much laboratory-scale ion implantation work, the savings in hardware simplicity and low cost may well more than compensate for this inconvenience. Since the overall device potential profile is in a sense the inverse of that conventionally employed, this set-up has been referred to as an «inverted ion implanter».

A simplified schematic of the setup is shown in Figure 8, and an outline of an implantation chamber as devised by Salvadori and coworkers in Figs. 9, 10 and $11[27,41]$. An outer cylindrical container is held at ground potential, in the front face of which is mounted the first grid. An inner cylindrical structure, well insulated from the outer grounded structure, is held at high negative voltage and the second extractor grid forms its entrance. The extractor is a multi-aperture configuration comprised of two grids, each having a large number of individual holes; good beam optics calls for appropriate extractor design, as discussed by many authors [42, 43]. A magnetically suppressed Faraday cup to monitor the implantation current density is located behind the target holder, with the holder geometry such that a known beam area is allowed to enter the cup.

An «inverted ion implanter» of this kind has been used to carry out implantation of gold into alumina, with $\mathrm{Au}$ ion energy $40 \mathrm{keV}$ and dose up to almost $1 \times 10^{17} \mathrm{~cm}^{-2}$. Resistivity of the metal-implanted ceramic was measured in situ as a function of dose and compared with predictions of a model based on percolation theory, in which electron transport in the composite is explained by conduction through a random resistor net- work formed by Au nanoparticles. Excellent agreement was found between the experimental results and a percolation theory [44]; see Fig. 12. In related work, Spirin and coworkers have used the «inverted implanter» approach to explore the formation of Ti/alumina nanocomposites by Ti implantation into alumina at energy of $52 \mathrm{keV}$ and dose up to $3.3 \times 10^{16} \mathrm{~cm}^{-2}$ [45].
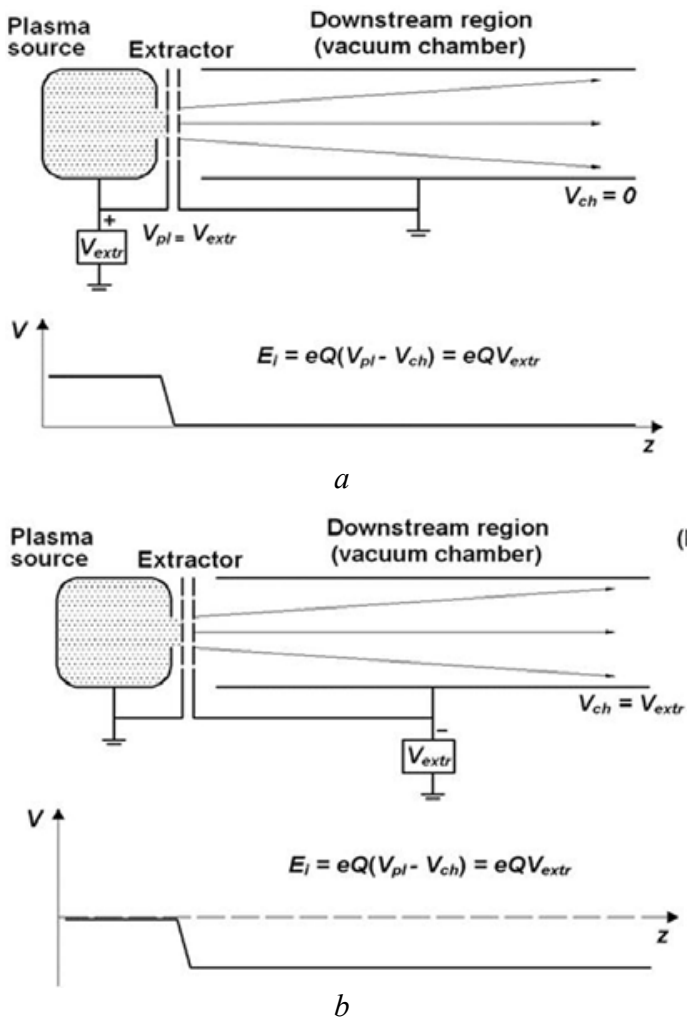

Fig. 8. Schematics showing the evolution of the conventional configuration (upper, $a$ ), in which the ion source is biased to high voltage, into the inverted ion implantation configuration

(lower, $b$ ), in which the ion source is at ground potential, a much simpler and lower cost configuration

The inverted ion source, and its embodiment as an inverted ion implanter, provides an excellent tool for ion implantation via a low cost, small laboratory scale, means.

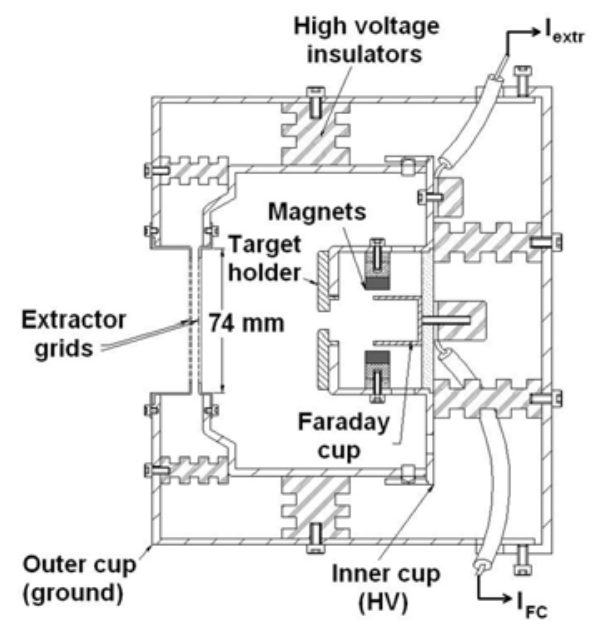

Fig. 9. Simplified schematic of an inverted ion implanter device 

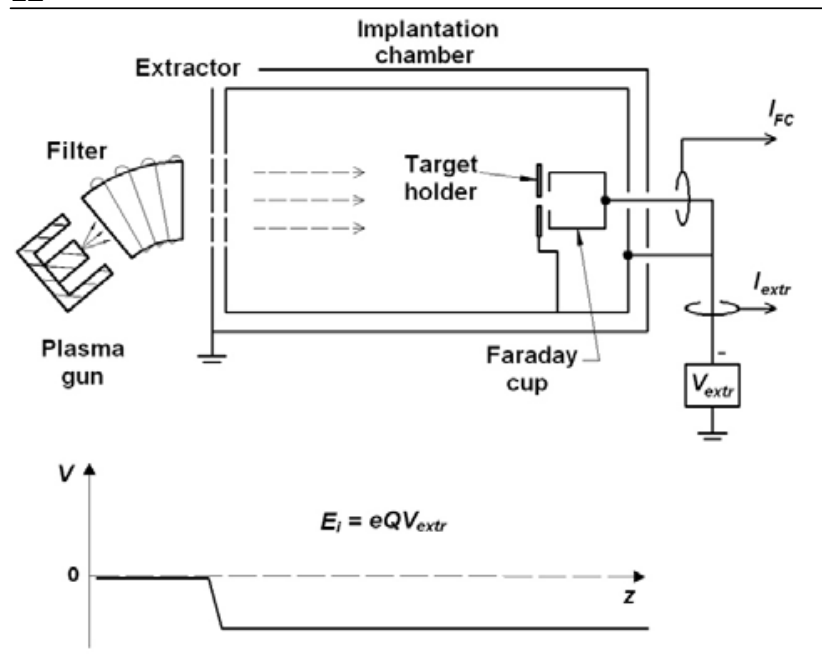

Fig. 10. Simplified schematic of the inverted ion implanter with filtered vacuum arc plasma gun, showing also the (on-axis) potential profile below ground

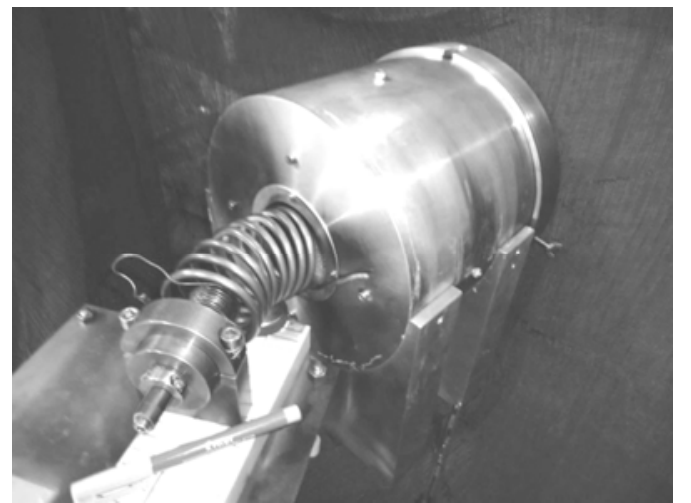

Fig. 11. Photograph of the inverted implanter with filtered vacuum arc plasma source; in operation this setup is housed within a larger vacuum chamber

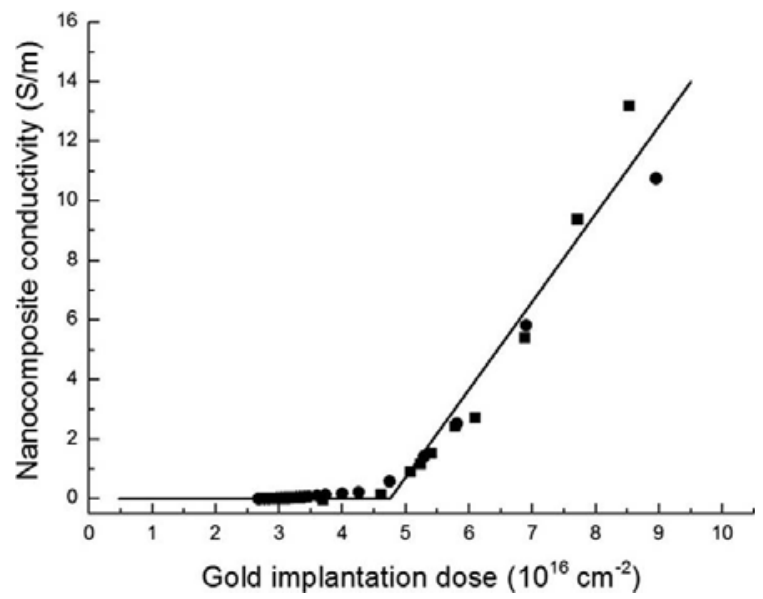

Fig. 12. Measured electrical conductivity of Au-implanted alumina as a function of implantation dose (black dots; two separate experiments), and the fit to a theory based on percolation (solid line)

\section{Conclusion}

The vacuum arc plasma source is unique among plasma formation systems in its prolific generation of metal (and carbon) plasma. This means of metal plasma generation has been used most effectively in a number of different ways for material surface modification, in systems employing both the «raw plasma» as well as ion source systems in which energetic ion beams are formed from the vacuum arc metal plasma. Here we have described four such approaches - energetic deposition of thin film structures using the filtered metal plasma from a vacuum arc plasma gun, metal ion implantation using the vacuum arc ion source, metal plasma immersion ion implantation and deposition (Mepiiid), and a simplified and low-cost approach to laboratory-scale metal ion implantation using the «inverted ion source» configuration with a vacuum arc plasma gun. Some examples have been provided of applications to which these tools have been put. The wider literature of a great array of applications, both research and commercial, is vast. It is probable that yet further novel plasma and ion source procedures employing vacuum arc plasmas remain to be invented and explored.

\section{References}

1. Lafferty, Ed., Vacuum arcs: theory and application. New York, Wiley, 1980. 228 p.

2. Boxman R.L., Martin P.J., Sanders D.M. Handbook of vacuum arc science and technology: fundamentals and applications. New Jersey, Publications, Park Ridge, 1995. 773 p.

3. Mesyats G.A., Cathode phenomena in a vacuum discharge: the breakdown, the spark, and the arc. Moscow, Nauka, 2000. 400 p.

4. Anders A. Cathodic arcs: from fractal spots to energetic condensation. New York, Springer, 2008. 544 p.

5. Anders A., Yushkov G.Y. Ion flux from vacuum arc cathode spots in the absence and presence of magnetic fields. J. Appl. Phys, 2002, Vol. 91, No. 8, pp. 4824-4832.

6. Brown I.G., Dickinson M.R., Galvin J.E., Godechot X., MacGill R.A. Some novel surface modification applications of a new kind of high current metal ion implantation facility. J. Mater. Eng., 1991, vol. 13, no. 3, pp. 217-228.

7. Brown I.G. Vacuum arc plasma guns and ion sources. Solid State Phenomena, 2005, Vol. 107, pp. 63-68.

8. Otooni M.A., Brown I.G., Anders S., Wang Z. Nanoscale multilayer materials for application in electromagnetic railgun systems. Mat. Res. Soc. Symp. Proc., 1996, vol. 396, p. 649.

9. MacGill R.A., Dickinson M.R., Anders A., Monteiro O.R., Brown I.G. Streaming metal plasma generation by vacuum arc plasma guns. Rev. Sci. Instrum, 1998, vol. 69, No. 2, pp. 801-803.

10. Brown I.G., Boxman R.L., Martin P., and Sanders D. Pulsed arc sources. Vacuum Arc Science and Technology, 1995. $235 \mathrm{p}$.

11. Brown I.G., Galvin J.E., Gavin B.F., MacGill R.A. A metal vapor vacuum arc ion source. Rev. Sci. Instrum, 1986, vol. 57, no. 6, pp. 1069-1084

12. Badgenov G.P., Bugaev S.P., Erokhin G.P., Kiselev V.N., Ligatchev A.E., Chesnokov S.M., Ianchiuck A.V. Metal ion source based on cold cathode vacuum arc. Proc. 5th All-Union Symp. High Current Electronics, 1984, pp. 93-95.

13. Bugaev S.P., Nikolaev A.G., Oks E.M., Schanin P.M., Yushkov G.Y. The 'TITAN' ion source. Rev. Sci. Instrum, 1994, vol. 65, no. 10, pp. 3119-3125.

14. Ryabchikov A.I. Emission properties of broad-beam vacuum arc ion sources. Rev. Sci. Instrum, 1992, Vol. 63, No. 4, pp. 2425-2427.

15. Brown I.G. Vacuum arc ion sources. Rev. Sci. Instrum, 1994, vol. 65 , no. 10 , pp. 3061-3081. 
16. Oks E.M., Brown I.G. Vacuum arc ion sources. The Physics and Technology of Ion Sources. Weinheim, Wiley, 2004. $396 \mathrm{p}$

17. Brown I.G., Oks E.M. Vacuum arc ion sources: a brief historical review. IEEE Trans. Plasma Sci, 1997, vol. 25, no. 6 , pp. $1222-1228$.

18. Brown I.G., Dickinson M.R., Galvin J.E., MacGill R.A. Development of a de broad beam Mevva ion source. Rev. Sci. Instrum, 1992, vol. 63, no. 4, pp. 2417-2419.

19. Brown I.G., Godechot X. Vacuum arc ion charge state distributions. IEEE Trans. Plasma Sci, 1991, vol. 19, no. 5, pp. 713-717.

20. Anders A. Ion charge state distributions of vacuum arc plasmas: the origin of species. Phys. Rev. E, 1997, vol. 55, no. 1, pp. 969-981.

21. Conrad J.R. Radtke J.L., Dodd R.A., Worzala F.J., Tran N.C. Plasma source ion-implantation technique for surface modification of materials. J. Appl. Phys, 1987, vol. 62, no. 11, pp. $4591-4596$.

22. Conrad J.R. Plasma source ion implantation: a new approach to ion beam modification of materials. Materials Sci. and Eng, 1989, vol. 116, pp. 197-203.

23. Mantese J.V., Brown I.G., Cheung N.W., Collins G.A. Plasma-immersion ion implantation. Plasma Processing of Advanced Materials. MRS Bulletin, 1996, vol. 21, no. 8, pp. 52-56.

24. Anders A. Handbook of plasma immersion ion implantation and deposition. New York, Wiley, 2000. 671 p.

25. Brown I.G., Godechot X., Yu K.M. Novel metal ion surface modification technique. Appl. Phys. Lett, 1991, vol. 58, no. 13, pp. 1392-1394.

26. Anders A. Metal plasma immersion ion implantation and deposition: a review. Surf. Coat. Technol, 1997, vol. 93, no. $2-3$, pp. $158-167$.

27. Salvadori M.C., Teixeira F.S., Sgubin L.G., Araujo W.W.R., Spirin R.E., Oks E.M., Brown I.G. Performance of an inverted ion source. Rev. Sci. Instrum, 2013, vol. 84, no. 2, pp. 023506.

28. Salvadori M.C., Teixeira F.S., Sgubin L.G., Cattani M., Brown I.G. Electrical conductivity of gold-implanted alumina nanocomposite. Nucl. Instrum. Meth. Phys. Res. B, 2013, vol. 310, pp. 32-36.

29. Anders A., Anders S., Brown I.G. Transport of vacuum arc plasmas through magnetic macroparticle filters. Plasma Sources Sci. Technol, 1995, vol. 4, pp. 1-12.

30. Schülke T., Anders A., Siemroth P. Macroparticle filtering of high-current vacuum arc plasmas. IEEE Trans. Plasma Sci, 1997, vol. 25, no. 4, pp. 660-664.

31. Anders S., Anders A., Yu K.M., Yao X.Y., Brown I.G. On the macroparticle flux from vacuum arc cathode spots. IEEE Trans. Plasma Sci, 1993, vol. 21, no. 5, pp. 440-446.

32. Anders S., Anders A., Ager J.W., Wang Z., Pharr G.M., Tsui T.Y., Brown I.G., Bhatia C.S. Mechanical properties of amorphous hard carbon films prepared by cathodic arc deposition. Mat. Res. Soc. Symp. Proc, 1995, Vol. 383, pp. 453.

33. Pharr G.M., Callahan D.L., McAdams S.D., Tsui T.Y., Anders S., Anders A., Ager J.W., Brown I.G., Bhatia C.S.,
Silva S.R.P., Robertson J. Hardness, elastic modulus, and structure of very hard carbon films produced by cathodic-arc deposition. Appl. Phys. Lett, 1996, vol. 68, no. 6, pp. 779-781.

34. Salvadori M.C., Teixeira F.S., Araújo W.W.R., Sgubin L.G., Brown I.G. Interface tailoring for adhesion enhancement of diamond-like carbon thin films. Diamond Relat. Mater, 2012, vol. 25, pp. 8-12.

35. MacGill R.A., Dickinson M.R., Brown I.G. Vacuum arc ion sources-micro to macro. Rev. Sci. Instrum, 1996, vol. 67 , no. 3, pp. 1210-1212.

36. Liu F., Dickinson M.R., MacGill R.A., Anders A., Monteiro O.R., Brown I.G., Phillips L., Biallis G., Siggins T. Surface resistivity tailoring of ceramics by metal ion implantation. Surf. Coat. Technol, 1998, vol. 103/104, pp. 46-51.

37. Gushenets V.I., Nikolaev A.G., Oks E.M., Savkin K.P., Yushkov G.Yu., Brown I.G. High-energy metal ion implantation for reduction of surface resistivity of alumina ceramic. Rev. Sci. Instrum, 2012, vol. 83, no. 2, pp. 02B908.

38. Salvadori M.C., Teixeira F.S., Araujo W.W.R., Sgubin L.G., Spirin R.E., Cattani M., Brown I.G. Gold nanoparticle formation in diamond-like carbon using two different methods: gold ion implantation and co-deposition of gold and carbon. J. Appl. Phys., 2012, vol. 112, no. 7, pp. 074312.

39. Möller W., Eckstein W. Tridyn: a TRIM simulation code including dynamic composition changes. Nucl. Instrum. Methods Phys. Res. B, 1984, Vol. 2, No. 1-3, pp. 814-818.

40. Möller W., Eckstein W., Biersack J.P. Tridyn: binary collision simulation of atomic collisions and dynamic composition changes in solids. Comput. Phys. Comm, 1988, vol. 51, no. 3 , pp. $355-368$.

41. Salvadori M.C., Teixeira F.S., Sgubin L.G., Araujo W.W.R., Spirin R.E., Oks E.M., Yu K.M., Brown I.G. Low cost ion implantation technique. Appl. Phys. Lett, 2012, vol. 101, no. 22, pp. 224104.

42. Spaedtke P. Computer simulation of extraction. The Physics and Technology of Ion Sources, 2004.

43. Green T.S. Intense ion beams. Rep. Prog. Phys, 1974, vol. 37, no. 10, pp. 1257.

44. Salvadori M.C., Teixeira F.S., Sgubin L.G., Araujo W.W.R., Spirin R.E., Cattani M., Oks E.M., Brown I.G. Gold ion implantation into alumina using an inverted ion source configuration. Rev. Sci. Instrum, 2014, vol. 85, no. 2, pp. 02B502.

45. Spirin R.E., Salvadori M.C., Teixeira F.S., Sgubin L.G., Cattani M., Brown I.G. Nanocomposite formed by titanium ion implantation into alumina. J. Appl. Phy., 2014, vol. 116 , No. 18 , p. 184306.

\section{Ian G. Brown}

Ph.D., Senior Physicist (retired), Lawrence Berkeley

National Laboratory, Berkeley, California, USA

Email: igbrown@comcast.net 